\section{EL PERIODISMO EN EL PRIMER TERCIO DEL SIGLO XX}

\author{
Alejandro Pizarroso Quintero \\ Dpto. Historia de la Comunicación Social \\ Facultad de Ciencias de la Información \\ Universidad Complutense de Madrid \\ Avda. Complutense, $s / n$ \\ 28040, Madrid \\ apizarroso@ccinf.ucm.es
}

\begin{abstract}
A study on the evolution of the press from the late 19th
\end{abstract} century to the beginning of the Spanish Civil War.

KEY WORDS: Ley de Prensa 1883 (Law Press-1883); newspapers and magazines; The Press Association; The Spanish Union of Journalists; The Church Journalism School; grand journalism companies; the press during Dictatorship; the press and the Republic.

Quiero que mis primeras palabras estén dedicadas a Carmen de Burgos que es quien nos congrega aqui hoy. Poco me voy a atrever a decir sobre ella. Voces más doctas lo han hecho y lo harán en estas jornadas. Y nada puedo añadir a la magnífica obra que sobre la escritora y periodista ha publicado Concepción Núñez Rey quien, junto con la profesora Palomo, coordina estas jornadas. A ambas mi agradecimiento por todo ello y por darme la oportunidad de compartir con vds. el interés por esta autora que merece ser rescatada de un olvido con el que la cultura española desdeña muchas veces algunos de sus mayores valores.

Como periodista colaboró en el recién nacido semanario $A B C$, también trabajó en el Diario Universal del que fue su primera redactora y en el Heraldo de Madrid, entre otras muchas colaboraciones. Fue una de las primeras mujeres corresponsales de guerra en nuestro país informando de la guerra de Marruecos en 1909. Pero no pretendemos ahora glosar su figura sino trazar brevemente un panorama del periodismo español en los años de la actividad de Carmen de Burgos. Nos referiremos fundamentalmente a la prensa escrita entre 1898 y 1931-32.

El siglo XIX es considerado el gran siglo de la prensa escrita. Este aserto es válido también para España. Los breves períodos de libertad de prensa son precedidos y sucedidos por largos períodos oscuros. Cuando en In-

\section{THE JOURNALISM IN THE FIRST THIRD OF THE $20^{\text {TH }}$ CENTURY}

RESUMEN: Se estudia la evolución de la Prensa en España desde finales del XIX hasta el inicio de la guerra civil.

PALABRAS CLAVE: Ley de Prensa de 1883; periódicos y revistas; Asociación de Prensa; Sindicato Español de Periodistas; la escuela de periodismo de la Iglesia; grandes empresas periodisticas; la prensa durante la Dictadura; la prensa y la República.

glaterra ya se puede hablar de una prensa industrial a finales del siglo XVIII, en España no podemos hacerlo hasta mediados del siglo XIX con la aparición del Semanario Pintoresco, Las Novedades y, sobre todo, La Correspondencia de España. Después de las convulsiones del Sexenio Revolucionario, la Restauración va a abrir un largo período de estabilidad política y libertad de expresión, sobre todo con la Ley de 1883, y ese período del último cuarto de siglo tradicionalmente considerado como la "edad de oro" de la prensa, también lo es para España, al menos para la España urbana, es decir, Madrid, Barcelona y poco más.

La peculiaridad -si es que se puede hablar de ella- del caso español, con respecto a la situación general europea en cuanto al desarrollo de la información, podemos cifrarla en una palabra que arrastramos hasta nuestros días: atraso.

Pero el siglo XX nos vuelve a jugar malas pasadas. España no está presente por suerte o por desgracia en los grandes acontecimientos del siglo. Se viven, eso sí, peculiar e

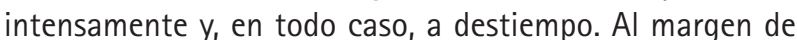
las dos guerras mundiales, tenemos que escenificar en casa un ensayo general de la segunda, y mientras toda Europa occidental se reconstruye con regímenes democráticos después de la Segunda Guerra Mundial, España vive uno 
de los períodos más abyectos de su historia, la dictadura del general Franco.

Para la prensa, sigue vigente el marco legal establecido por la Constitución de 1876 y la Ley de Prensa de 1883. Este sistema, esencialmente liberal, iba a sufrir no despreciables restricciones tanto con la Dictadura como antes de ella, para desaparecer luego con el nuevo régimen republicano. El siglo comienza con la ley de Jurisdicciones de 23 de marzo de 1906, por la que quedaban sometidos a los tribunales militares los delitos contra la patria y el ejército, que estará vigente hasta la República y que desde su promulgación provocó una oleada de protestas en el mismo Parlamento y en la prensa.

En todo este período conviven en la prensa española características heredadas del siglo XIX con nuevos planteamientos más acordes con el siglo XX. La prensa de información basada en empresas con serios planteamientos de financiación, que ya había empezado a desarrollarse en la segunda mitad del siglo anterior, coexiste con una prensa política, no ya de partido, sino de fracciones o de hombres, sin viabilidad económica, que todavía es predominante en cuanto al número de cabeceras a principios de siglo.

Poco a poco la situación se invertirá. Así, si en 1913, dentro de las 1.980 cabeceras de todo tipo que se publicaban, podemos considerar a 156 de ellas como periódicos de información frente a 586 periódicos políticos; en 1920 las cifras se acercarán sensiblemente (339 periódicos políticos frente a 283 de información). Para llegar en 1927 a 327 periódicos de información frente a 210 políticos.

La profesión de periodista estaba todavía más en el siglo XIX que en el XX. En 1895 y 1899 se habian intentado crear sindicatos de periodistas y en 1895 Miguel Moya creará en Madrid la "Asociación de la prensa" con fines que no iban más allá de la beneficencia. En 1919 se constituyó el Sindicato Español de Periodistas adherido a la UGT y presidido por Ezequiel Eudériz, redactor de EI Liberal. Durante la Dictadura existió un proyecto de Estatuto de Prensa de inspiración mussoliniana que preveía incluso crear escuelas de periodismo en las facultades de Filosofía de Madrid, Barcelona y Sevilla, pero que no llegó a presentarse a la Asamblea Nacional, pues antes cayó el régimen. Sí funcionaron, en cambio, los Comités Paritarios de Prensa que ciertamente consiguieron mejorar en algo las condiciones de trabajo, contratos, salarios, vacaciones, etc. de los periodistas. Ángel Herrera Oria, director del diario católico-conservador El Debate, fundaría en 1924 la "Escuela de Periodismo de la Iglesia".

A pesar de que el gran número de publicaciones puede darnos la idea de un gran auge de la prensa en este primer tercio del siglo, lo cierto es que predominaban las pequeñas empresas. Muchas de estas publicaciones tenían muy corta vida. Además, el analfabetismo restringía mucho el público potencial. En los tres primeros lustros del siglo se pasó en España de 1.347 periódicos en 1900 a 1.980 periódicos en 1913 (es decir, de un periódico por cada 15.106 habitantes, a uno por cada 10.076; cifras que en Madrid se reducían a uno por 1.914 hab. y en Barcelona a uno por 3.535 hab.).

Si consideramos el período 1914-1931, las cifras siguen mostrando un aumento del número de publicaciones hasta 1920 (2.289 periódicos) que, en cambio, baja en 1927 (2.210; un periódico por cada 10.176 hab.). Esto último se debe quizá a la Dictadura, aunque también podemos empezar a hablar de concentración de empresas. En 1927 los diarios representaban un $12,67 \%$ de las publicaciones entre las que predominaban las mensuales, mientras que en 1913 los diarios eran un 16\% y predominaban los semanarios. Desvois calcula entonces una tirada media para los diarios de 4.800 ejemplares lo que teniendo en cuenta las altas tiradas de algunos diarios de Madrid daría para la mayoría de las publicaciones diarias cifras ínfimas.

En torno a 1920 la mayoría de los grandes diarios no habian aumentado su número de páginas, que en general eran ocho, lo que les daba espacio suficiente para una presencia cada vez mayor de la publicidad. Ésta era, cada vez más, uno de sus recursos financieros más importantes. De 1913 a 1920 se producen también importantes progresos en los recursos materiales: de 36 rotativas y 15 linotipias en 1913 se pasa en 1930 a 31 y 213, respectivamente. En 1930, 565 publicaciones disponían de imprenta propia mientras que en 1913 sólo eran 270.

De etapas anteriores sobrevivieron todavía grandes empresas periodisticas que pronto iban a tener que competir con nuevas cabeceras. Así, La Correspondencia de España, que indudablemente era la primera empresa periodística digna de ese nombre que había existido en España, ha- 
bía ya perdido la primacía frente a El Imparcial y, para frenar su decadencia, fue nombrado director Leopoldo Romeo que no pudo cumplir su objetivo de recuperarlo. Aún así se mantuvo languideciendo hasta 1925 en que desapareció.

El Imparcial habia superado a La Corres y estaba en su apogeo a principios de siglo. Pero la independencia que le había dado su prestigio desapareció a ojos del público cuando su director Rafael Gasset -hijo del fundador- fue nombrado ministro de Fomento por Francisco Silvela en abril de 1900. Tenía entonces una tirada de 130.000 ejemplares que bajó a 80.000 en 1906. Después de la experiencia del llamado "trust de los periódicos", estuvo a punto de ser controlado por Urgoiti, operación que fracasó, dando lugar a una verdadera escisión de la que surgiría El Sol. El Imparcial, en franca decadencia, se mantuvo como una caricatura de sí mismo hasta 1933.

El Liberal, moderadamente republicano y anticlerical, se hizo pronto un diario verdaderamente popular, acérrimo defensor de la libertad de prensa y modelo de equilibrio entre la seriedad informativa y la amenidad. Su éxito le permitió fundar en 1901 en Barcelona, Sevilla y Bilbao tres periódicos de su mismo nombre. Compró, además, Las Provincias de Levante de Murcia que en 1902 pasó también a llamarse El Liberal. Formó parte del "trust" y tuvo, claro es, una postura aliadófila durante la Gran Guerra. En diciembre de 1919, a raíz de la huelga de periodistas, se separaron de El Liberal un grupo de redactores para fundar La Libertad. Este golpe contribuyó también a la crisis del "trust". Por sus posturas radicales sufrió también la hostilidad de la Dictadura.

El vespertino Heraldo de Madrid pasó, con el nuevo siglo, a manos de José Canalejas y lo dirigió José Francos Rodríguez hasta que en 1906 fue comprado por la Sociedad Editorial de España (el "trust"). Muy popular, verdadero "gorro de dormir" de los madrileños, mantuvo siempre posturas progresistas y por ello tuvo muchas dificultades durante la Dictadura. Su último número se publicó el lunes 27 de marzo de 1939, víspera de la ocupación de Madrid.

Mencionamos, por último, el único que sobrevive en nuestros dias: La Vanguardia de Barcelona. En 1887 lo compró Carles Godó Pie y desde 1888 se convirtió en diario de información independiente aunque siempre próximo al
Partido Liberal. Pero esta situación cambió cuando, a la muerte de Carles Godó, fue sucedido en 1897 por su hijo Ramón Godó Lallana (amigo de Maura) que inclinó el diario hacia el conservadurismo.

A estas grandes empresas periodísticas cuyo origen estaba en el siglo anterior vinieron a sumarse otras nuevas que iban a jugar un papel trascendente en la prensa española del siglo XX.

La primera de ellas, al menos cronológicamente, será "Prensa Española" editora del semanario Blanco y Negro y del diario $A B C$. Blanco y Negro había nacido en 1891 fundado por Torcuato Luca de Tena y Álvarez Ossorio. La operación que dio a luz el diario $A B C$ no estuvo exenta de dificultades. La nueva publicación, a falta de rotativa, y en las máquinas planas de Blanco y Negro, sólo pudo nacer como semanario el 1 de enero de 1903, más ligero, barato y popular que su hermano mayor. Del 1 de junio de 1903 a marzo de 1904 fue bisemanal, de marzo a diciembre de 1904 volvió a ser semanario. Desapareció entonces hasta el 1 de junio de 1905 en que pudo salir definitivamente como diario. Nació $A B C$ con ambiciosas pretensiones. Su éxito de tirada fue grande (50.000 ej. al cabo de un mes) pero sus pérdidas también lo eran. En efecto, la abundancia de información gráfica, la excelente plantilla de redactores muy bien pagados y otros dispendios elevaban su presupuesto mensual en 1906 a 150.000 pesetas, cifra enormemente alta para la época. Pero pronto pudo obtener beneficios. Sin vinculación a ningún partido, su postura en todo momento fue -y es- inequívocamente conservadora y monárquica.

El 1 de octubre de 1910, fundado por Guillermo de Rivas, iba a surgir El Debate con el subtítulo de Diario de la mañana, católico e independiente. Su primer director iba a ser el religioso Basilio Álvarez. En 1911, Rivas hubo de cedérselo a Santiago Mataix, propietario de El Mundo con quien había contraído fuertes deudas. No mejoró su escaso éxito y Mataix acabó vendiéndoselo a Ángel Herrera Oria en noviembre de 1911 quien lo dirigiría desde entonces hasta febrero de 1933. Su éxito no fue entonces inmediato. Distintas dificultades financieras llevarían a uno de los socios iniciales de Herrera -el diario católico La Gaceta del Norte, de Bilbao- a ceder su participación a otro de los socios, la Asociación Católica Nacional de Propagandistas. Con nuevos socios capitalistas se fundó en 1913 la

ARBOR CLXXXVI EXTRA JUNIO 2010 45-54 ISSN: 0210-1963

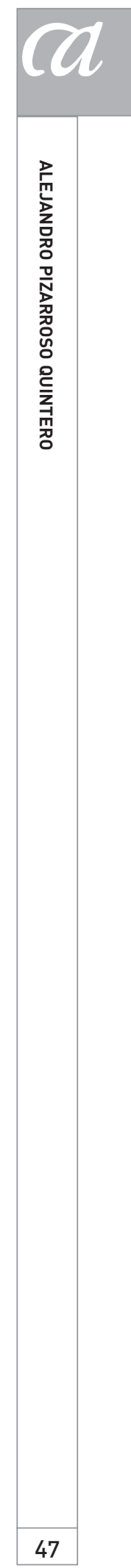


Editorial Católica que, desde entonces, se encargó de la edición del diario.

El Debate se sometía a la censura eclesiástica y mantuvo siempre una posición ultraconservadora. Ángel Herrera se rodeó de un gran equipo de periodistas. Durante la Gran Guerra el diario fue abiertamente germanófilo y los artículos de "Armando Guerra" (el comandante de Estado Mayor, Francisco Martín Llorente), atinado comentarista militar, hicieron pasar rápidamente su tirada de 8.000 ejemplares a 50.000 en 1916. En vísperas de la República su tirada casi alcanzaba los 80.000 ejemplares.

Hasta el advenimiento de la República aparecerán todavía otros grandes diarios: La Libertad (1919), Informaciones (1922) y La Nación (1925) este último, órgano oficioso de Primo de Rivera; además del excelente El Sol (1917).

Acabamos de ver cómo la empresa de El Liberal se había extendido a diversas provincias. En 1906, Miguel Moya y Antonio Sacristán quisieron ir más lejos y se asociaron con los Gasset de El Imparcial para dar paso a la Sociedad Editorial de España que desde sus orígenes iba a ser popularmente conocida como el "trust de los periódicos". El primer Comité Ejecutivo de la sociedad estaba presidido por Miguel Moya con José Ortega Munilla (vicepresidente), José Gasset y Chinchilla (secretario) y Antonio Sacristán (inspector gerente). El capital estaba inicialmente dividido en 4.500 acciones de 1.000 ptas., de las cuales 2.100 eran de los Gasset y 2.500 de la sociedad de El Liberal.

El Imparcial buscaba en esta asociación remedio a su crisis de decadencia, pero lo cierto es que el asociarse dos diarios de la mañana, competidores en tantos terrenos, podía parecer "contra natura". Hubo también negociaciones con el viejo La Correspondencia de España y con el nuevo $A B C$, pero no llegaron a buen término. La operación iba a completarse con la compra de el Heraldo de Madrid por un millón y medio de pesetas, que pagaron al contado a Canalejas gracias a un préstamo de un industrial murciano, José Maestro, que devolvieron, gracias a los beneficios, a los pocos meses. Así, con El Liberal y su cadena, El Imparcial y el Heraldo de Madrid nació el "trust". Cada periódico siguió manteniendo su propia personalidad, El Imparcial era liberal dinástico, El Liberal, republicano y progresista, el Heraldo, progresista y muy popular, pero el "trust" acumulaba suficiente poder para ser interlocutor a tener en cuenta en muchos terrenos. Precisamente esa fuerza, que a los lectores daba la impresión de un monopolio, agravó aún más la crisis del El Imparcial que lastró el éxito económico de la operación.

Francos Rodríguez, que, en principio, habia desaconsejado a Canalejas la venta de el Heraldo, una vez que se consumó ésta, aceptó sin vacilación continuar dirigiéndolo. Así pues, el nacimiento de la sociedad editorial no llevó a ningún cambio en la dirección de los periódicos que la integraban.

El "trust" amplió su red provincial con la adquisición de $E I$ Defensor de Granada en 1907 y El Noroeste de Gijón en enero de 1908. Controlaba, pues, nada menos que nueve diarios, cuatro de ellos en Madrid.

La primera demostración de fuerza del "trust" fue a causa del precio del papel. La Papelera Española, fundada en 1901, estaba presidida en 1906 por Nicolás María de Urgoiti. Con claros objetivos monopolistas habia hecho descender el precio del papel en un 20\%. El recién constituido "trust" exigió nuevas reducciones. El Gobierno, del que formaba parte Rafael Gasset, iba a proponer a las Cortes un arancel proteccionista para el papel. El Imparcial inició una campaña contra éste y contra el monopolismo de La Papelera. Urgoiti replicó desde el $A B C$. Finalmente el arancel no se aprobó y el precio del papel de prensa bajó. El "trust" se habia impuesto.

El contrato fundacional de la Sociedad Editorial de España tenía una duración prevista de diez años, y la vida del "trust" no iba a prolongarse más allá. Desde el comienzo había despertado numerosos recelos. La Correspondencia de España comenzó a incluir en su cabecera un entrefilete que rezaba: "Este periódico no pertenece al 'trust'". En ello sería imitada por muchos otros. El Imparcial sería el más dañado como periódico en la aventura y el primero que saldría de la sociedad. La familia Gasset (con la Sociedad de El Imparcial) recuperaría el control del periódico en marzo de 1936, en cuya cabecera aparecería, desde el mes siguiente, la misma frase de La Correspondencia.

La Sociedad Editorial de España subsistirá con los restantes diarios -además de La Moda Práctica- hasta 1922. Desde el fallecimiento de Miguel Moya en 1920 entró en una acelerada crisis económica. Se harían con ella sus acreedo- 
res, Manuel y Juan Busquets. Pasa entonces a denominarse Sociedad Editora Universal.

Nicolás María de Urgoiti era consciente de que a su imperio industrial le hacía falta contar al menos con un periódico que defendiera sus intereses. Había pretendido comprar $A B C$ sin conseguirlo y pensaba también fundar un nuevo diario. Cuando El Imparcial se separó del "trust", fue el mismo Rafael Gasset quien buscó su apoyo financiero para renovar el periódico. Se llegó a un acuerdo y hubo un contrato privado. Cuando Urgoiti comenzó a intervenir directamente, sobrevino la ruptura y no hubo escritura pública. Urgoiti denunció a los Gasset e intentó represalias económicas, pero todo fue inútil.

El mismo grupo que había intentado controlar El Imparcial creó el 16 de noviembre de 1917 la Sociedad El Sol. Tras dos meses de preparativos y con grandes inversiones, el 1 de diciembre de 1917 iba a salir a la calle El Sol, el periódico cuya calidad iba a estar por encima de todo lo hecho hasta entonces en España.

Eran 12 páginas en gran formato donde no cabían ni la información taurina ni la lotería. Tenía abundante información local, de provincias y del extranjero. Desde enero de 1918 publicaba suplementos semanales dedicados los domingos a la agricultura y la ganadería; los lunes, a la pedagogía y la instrucción pública; los martes, a la biología y la medicina; los miércoles, a las ciencias sociales y económicas; los jueves, a la historia y la geografía; los viernes, a la ingeniería y arquitectura, y los sábados, al derecho y a la legislación.

Costaba el doble que los demás periódicos, una perra gorda, y buscaba un público de intelectuales y de lo más liberal y abierto de la burguesía. Su director fue Félix Lorenzo, y José Ortega y Gasset escribía en él casi diariamente. Contaba con el excelente dibujante Luis Bagaría. La lista de las grandes firmas que llenaron sus páginas serían una representación de lo mejor de la intelectualidad española de la época: Mariano de Cavia, Corpus Barga (corresponsal en París), Julio Álvarez del Vayo (corresponsal en Ginebra), Salvador de Madariaga, Julio Camba, Federico de Onís (corresponsal en Nueva York), etc.

En 1920, Urgoiti, para equilibrar el presupuesto deficitario de El Sol, lanzó un diario de la noche: La Voz. Sus posiciones eran análogas a las de su hermano mayor pero expuestas de manera más amena y sencilla. Fue un buen periódico popular en el que colaborarian firmas que también lo harian en El Sol. Enrique Fajardo ("Fabián Vidal") fue su director y Manuel Bueno su redactor jefe.

El Sol mantuvo inicialmente frente a la Dictadura una postura de benevolente expectativa, que fue luego de crítica y oposición. Cuando cayó ésta adoptó una postura decididamente republicana. Es famoso el artículo de Ortega y Gasset, "El error Berenger" que concluía con la lapidaria frase: "Delenda est Monarchia". Desde Palacio llegaron amenazas a La Papelera de represalias económicas. Urgoiti había cedido a ésta -para satisfacer deudas- un paquete de acciones de El Sol por lo que en su Consejo de Administración habian entrado hombres como Arteche, Arosti y Rodríguez Acosta. En marzo de 1931 el diario cayó en manos de un grupo de monárquicos donde figuraban los condes de Gamazo y Barbate, José Félix de Lequerica y otros. Con El Sol Urgoiti perdió también La Voz.

Félix Lorenzo, Ortega y Gasset y la mayoria de los hombres de El Sol siguieron a Urgoiti que fundó en abril de 1931 la editorial Fulmen. Tres días después del último número de El Sol de Urgoiti y Ortega, salía a la calle el trisemanal Crisol, el sábado 4 de abril de 1931, que se convertiría en el diario Luz (con el subtítulo de Diario de la República) el 7 de enero de 1932. Pero no acabaron ahí las dificultades de Urgoiti, que terminaría vendiendo Luz en septiembre de 1932 a Luis Miquel quien ya se había hecho con El Sol y La Voz. Félix Lorenzo que había dirigido Crisol y Luz cedió su puesto a Luis Bello.

Otros dos importantes diarios iban a surgir antes de la Dictadura: La Libertad e Informaciones. La Libertad había surgido el 13 de diciembre de 1919, a partir de un grupo de redactores separados de El Liberal. La nueva sociedad editora la formaban Eduardo Ortega y Gasset, Luis de Oteiza, Antonio de Lezama, Luis Zulueta y Antonio Zozaya, inicialmente, aunque éste último muy bien pudo haber sido el hombre de paja de Santiago Alba, Juan March y Horacio Echevarrieta. El Liberal le puso pleito por la cabecera que hubo de modificarse temporalmente en El Popular. Con una tirada que llegó a los 90.000 ejemplares, defendía una política de reformismo burgués moderado en línea con Santiago Alba. Era un gran diario de información con 
numerosas secciones, dirigido por Joaquín Aznar y con Antonio Lezama como subdirector.

En 1922, Rafael Barón y Martínez Agulló fundaron con un capital de 100.000 pesetas Informaciones con clara inclinación derechista. Fue su primer director Leopoldo Romeo (que dejó para ello la dirección de La Corres, ya agonizante). Más tarde sería adquirido por Juan March y mantendría una posición antirrepublicana.

Durante la Gran Guerra, la avidez de información, estimulada por los acontecimientos bélicos, favoreció inicialmente a toda la prensa. Todos los diarios políticos aumentaron sus tiradas y se alinearon unos con la Entente y otros con los Imperios centrales. Eran germanófilos: $A B C, L a$ Acción, El Correo Español, El Debate, El Día, El Mundo, El Parlamentario, El Siglo Futuro y La Tribuna. Eran aliadófiIos: La Correspondencia de España, España Libre, Heraldo de Madrid, El Imparcial, El Liberal, La Mañana, El País, El Radical y El Socialista.

Las embajadas de los países beligerantes, sobre todo la alemana, fueron generosas con los periodistas para favorecer el desarrollo de una opinión pública en España favorable a sus intereses (sobre todo la no entrada en guerra en el bando contrario).

De todos modos, los beneficios obtenidos del aumento de las tiradas no compensaban el aumento de los costes. El papel, al desaparecer prácticamente las importaciones, casi duplicó su precio (un 80\% de aumento entre 1913 y 1916) en un mercado dominado por la Papelera Española de Urgoiti. El gobierno intentó paliar la situación con la concesión de anticipos reintegrables a las empresas periodísticas para sus compras de papel (ley de 29 de julio de 1918) a lo que algunos periódicos no se acogieron, como El Socialista (que se endeudó), La Vanguardia (que tenía una fábrica de papel propia), o El Sol (que también se endeudó con La Papelera). El resultado final fue el aumento del precio de los diarios ya acabada la guerra.

En 1915, Nicolás María de Urgoiti afirmaba en una conferencia que en España había 300 diarios de los que sólo un centenar superaba los 2.500 ejemplares, con una tirada total de 1.200 .000 ejemplares (500.000 en Madrid, 200.000 en Barcelona y 500.000 en el resto de España). De todos modos, no existían medios para controlar las tiradas y la tensión entre los gastos producidos por el aumento de circulación y los ingresos por la publicidad creaban no pocas dificultades a los periódicos.

Cuando Primo de Rivera tomó el poder, una de sus primeras medidas fue la de establecer la censura previa, aunque la Constitución de 1876, que la prohibia expresamente, continuaba en vigor. De todos modos, la mayoría de los periódicos adoptaron una actitud expectante sin enfrentarse con la nueva situación. Es cierto también, por otra parte, que en sus primeros momentos el nuevo régimen no tiene un perfil definido y parece orientarse hacia una renovación del sistema parlamentario; todavía no había adquirido el sesgo fascista de sus últimos años.

El mismo dictador va a hacer frecuentes incursiones en la prensa sin el menor sentido del ridículo. En 1925 impulsará el nacimiento de un órgano oficioso: La Nación. Para ello se fundará "Editorial La Nación S.A.". La tirada del periódico no superó la de los grandes diarios pero alcanzó los 55.000 ejemplares. Sobrevivirá al régimen como órgano de la extrema derecha durante la República. En sus páginas se dio un caso famoso: en 1929 publicó un soneto en alabanza al Dictador que había sido remitido conteniendo un acróstico que rezaba: "Primo es borracho".

Los periódicos de información, sobre todo los de talante más liberal, se distanciaron rápidamente del régimen y sufrieron por ello numerosas multas y suspensiones. Podemos hablar, pues, de una prensa de oposición que circulaba legalmente: El Sol y su vespertino La Voz, también el Heraldo de Madrid y La Libertad, además de algunos otros periódicos de provincias, no claudicaron ante la Dictadura lo que les trajo enormes dificultades.

Contaba el régimen con el apoyo de la prensa más conservadora, con El Debate y el $A B C$, además, por supuesto, de La Nación. También le apoyaba el Informaciones, diario de la noche fundado en 1922 por Rafael Barón y Martínez Agulló, cuyo primer director fue Leopoldo Romeo.

La prensa obrera vivía a caballo entre la legalidad y la clandestinidad. Perseguidos los órganos anarquistas o comunistas, tolerados, en cambio, los socialistas por la colaboración del PSOE y de la UGT. En efecto, El Socialista no dejó de publicarse. 
Caído ya el Dictador, iba a nacer en diciembre de 1930 un nuevo periódico de información, moderado, que alcanzaría gran popularidad. Nos referimos a Ahora. Fundado por Luis Montiel Balanzat que provenía del ciervismo y que habia hecho fortuna en negocios papeleros; su primer redactor jefe fue Chaves Nogales. Su éxito fue fulminante: en enero de 1931 afirmaba tener una tirada de 159.289 ejemplares.

Los primeros años del siglo vieron nacer numerosas revistas más o menos literarias que podemos encuadrar en el impulso de la Generación del 98. Así, en 1901 Francisco ViIlaespesa funda la efímera Electra donde colaboró Maeztu, y en 1902 nace la revista Ibérica. En 1903 surgirian Helios (modernista) o Alma Española (situada más a la izquierda). Como revista literaria imprescindible continuaba Los lunes del Imparcial.

Entre los semanarios ilustrados destaca Blanco y Negro, fundado en marzo de 1891 y que, posiblemente, será la revista gráfica más importante de los primeros lustros del siglo XX. Antes, en 1889, Manuel Alhama Montes ("Wanderer") habia fundado Alrededor del Mundo que se publicaría hasta 1930. En 1894 surgió por obra de José del Perojo Nuevo Mundo. Perojo falleció en 1908 y en 1911 un grupo de colaboradores de la revista y de Por esos Mundos (nacida como su suplemento en 1900 y desde 1906 mensual independiente) fundaron Mundo Gráfico que absorbería a las dos anteriores en 1913.

En 1915 José Ortega y Gasset, con el apoyo financiero de Luis García Bilbao, iba a fundar la revista España con el subtítulo de Semanario de la vida nacional. Entre sus primeros redactores figuraron Pío Baroja, Ramiro de Maeztu, Ramón Pérez de Ayala y otros, además de una lista de destacadísimos colaboradores.

Ortega fundó en 1916 El Espectador de la que sería redactor único. Había abandonado España por su orientación cada vez más a la izquierda, bajo la dirección de Luis Araquistáin a quien sucedería en 1922 Manuel Azaña. El Espectador dejó de publicarse en 1924.

En este campo de la prensa semanal tienen una importante presencia las revistas de espectáculos y toros y la incipiente prensa deportiva, además de la prensa femenina o de modas. En cuanto a esta última podemos mencionar Friné en Madrid o El Eco de la Moda en Barcelona además de otras muchas quincenales o mensuales.

Solamente en Madrid entre 1900 y 1936 nacieron 141 publicaciones taurinas, muchas de ellas efímeras ciertamente pero que nos dan idea de la pujanza de este tipo de prensa. Cabeceras como Sol y Sombra (abril 1897-junio 1926) y El Eco taurino (1910-1946) o La Lidia, en Madrid; La Corrida en Barcelona; Caireles en Málaga; Pitos y Palmas en Zaragoza, etc. son sólo una muestra de la enorme pujanza que este tipo de prensa tuvo en el primer tercio del s. XX.

Análoga consideración tendrian para nosotros publicaciones dedicadas al teatro, o a los espectáculos en general, así como las primeras publicaciones dedicadas al cine. Hay que mencionar además la incipiente prensa deportiva con cabeceras como Los Sports, semanario fundado en 1916, - Eco de Sports (de 1919), ambos en Madrid, además de Foot-Ball de Barcelona.

En un terreno totalmente distinto habría que referirse a la mensual Revista de Occidente de José Ortega y Gasset, fundada en 1923 que tuvo enorme influencia en la vida intelectual y política de su tiempo.

Buena parte de la historiografía actual se refiere a la Segunda República española como una "República de periodistas". Efectivamente en las Cortes Constituyentes de 1931 se sentaban 47 periodistas. Después de los catedráticos de Universidad constituian el grupo profesional más numeroso, excepción hecha naturalmente de los abogados.

Ciertamente, la accidentada vida de la Segunda República española no le permitió ser un ejemplo de libertad de expresión inmaculada. La censura siguió funcionando de hecho, las medidas de carácter represivo se prodigaron. De todos modos -y sobre todo visto desde la actualidad- los periódicos de entonces atacaban a sus adversarios con una agresividad que ahora nos parecería inconcebible. La violencia acumulada en la sociedad española, de la que la prensa no era sino mero reflejo, iba a desembocar en una ruptura definitiva: el levantamiento militar contra el Gobierno legalmente constituido iba a truncar definitivamente el penúltimo intento de modernización de España. 
La mayoría de los grandes periódicos acogió esperanzado la nueva situación surgida de las elecciones municipales del 12 de abril de 1931. Incluso entre los periódicos abiertamente monárquicos, El Debate, aplicando la doctrina del gobierno "de hecho" de León XIII, acató el nuevo régimen. $A B C$, en cambio, se mostró reticente desde el primer momento.

El Gobierno provisional asumió todos los poderes y dictó una amplia amnistía. Ya en el Estatuto Jurídico Provisional que iba a regir la vida política hasta la proclamación de la nueva Constitución en diciembre de 1931, se reconocian todos los derechos individuales, naturalmente también el de expresión, aunque el Gobierno se reservaba un "régimen de fiscalización" de estos derechos.

En el proyecto constitucional, el artículo 34 sancionaba la libertad de expresión y en el artículo 10 se decía que "Corresponde al Estado español la legislación y podrá corresponder a las Regiones autónomas la ejecución en la medida de su capacidad política a juicio de las Cortes, sobre las siguientes materias: (...) 10. Régimen de prensa. Asociaciones, reuniones y espectáculos públicos".

A raíz de la quema de conventos de 11 de mayo fueron suspendidos los diarios $A B C$ y El Debate. El primero reaparecería el 3 de junio y el segundo, el 20 de mayo.

Poco después de la aprobación del artículo 26 de la Constitución relativo a la cuestión religiosa se pasó a discutir un proyecto de ley denominado "de Defensa de la República" promulgada el 24 de octubre en la que se consideraban actos de agresión a la República el difundir noticias que pudieran perturbar la paz y el orden público. Gracias a esta ley fueron numerosas las multas y suspensiones a derecha y a izquierda.

Poco antes de proclamarse la República, El Sol y La Voz, como hemos visto, habían sido adquiridos por un grupo de personalidades monárquicas. De todos modos ambos periódicos se adhirieron al nuevo régimen. Dentro del panorama de la prensa diaria durante la República el diario Ahora ocupa un lugar destacado. Comenzó a publicarse el 16 de noviembre de 1930, coincidiendo con la sublevación republicana de Jaca. Nació con una intención clarisima de competir desde posiciones más progresistas con el diario $A B C$. Aunque de tamaño algo mayor, Ahora imprimía también varias páginas en huecograbado y su portada la ocupaba siempre una fotografía de actualidad. Hizo gala también al principio de fidelidad monárquica que luego se trocaría en respeto por el nuevo régimen republicano.

El diario Ahora era propiedad de Luis Montiel Balanzad al que, más que periodista tendriamos que denominarle empresario periodístico, habiendo comenzado en la industria papelera y luego de artes gráficas. Montiel habia lanzado en 1926 el diario literario La Novela Mundial al que siguieron otros y finalmente en enero de 1928 la revista semanal Estampa. A Montiel se debe también una de las más populares publicaciones deportivas españolas: el semanario AS que apareció en junio de 1932.

Ante el peligro de verse desbordada por la izquierda o por la derecha, la República necesitaba de una prensa adicta. Después de la aventura de Crisol, Urgoiti habia fundado el diario Luz con una importante participación de la "Agrupación al servicio de la República", con José Ortega y Gasset, Gregorio Marañón y Ramón Pérez de Ayala. Luz, como antes El Sol y Crisol, iba a ser dirigido por Félix Lorenzo.

El Socialista comenzó en septiembre de 1932 a airear la noticia de que, financiado por el acaudalado Luis Miquel, se iba a constituir un "trust" periodístico con El Sol, La Voz y Luz. A pesar de los desmentidos, todo era cierto.

El mejicano Martín Luis Guzmán, que había sido secretario de Pancho Villa y que contaba entonces con la confianza de Azaña, puso a éste en contacto con Luis Miquel. Tras el fracaso y la sublevación del 10 de agosto, Miquel logró hacerse con la propiedad de El Sol y de La Voz, al parecer con la amenaza de implicar a sus propietarios monárquicos en la intentona. El 14 de septiembre, Luz anunciaba el "concurso de capitales nuevos" que lo vigorizarían y el cambio, "por razones de salud", del director Félix Lorenzo al que sustituiría Luis Bello.

Con Luis Miquel como presidente del Consejo de Administración y Martín Luis Guzmán como gerente, quedó efectivamente constituido el "trust" que agrupaba a los tres periódicos. De todos modos, la aventura iba a terminar en un fracaso económico. Además, Bello iba a tener serias discrepancias con los miembros socialistas del Gobierno, lo que llevaría a su cese al frente de Luz el 8 de marzo 
de 1933, provocando una seria crisis en la redacción: el propio Luis Miquel iba a ser obligado a asumir la dirección y Nicolás M.a Urgoiti la subdirección. Poco después, Miquel perdió la propiedad de El Sol y La Voz por edicto del Juzgado de Primera Instancia n. 6 de Madrid. La nueva empresa designó como director de El Sol a Fernando García Vela, fiel colaborador de Ortega y Gasset, y confirmó en La Voz a Enrique Fajardo ("Fabián Vidal"). El diario Luz en cuya dirección había sucedido a Miquel, "Corpus Barga", dejó de publicarse el 8 de septiembre de 1934.
Pero Colombine fallece en 1932 y por ello queremos detenernos aqui en este apresurado panorama de la prensa española en le primer tercio del pasado siglo, como marco a la actividad periodistica y literaria de Carmen de Burgos.

Quedan en el tintero aspectos tan importantes como el nacimiento del cine en España (informativo y de ficción), los primeros pasos de la radio y el periodismo de agencia. Pero eso sería abusar de su paciencia.

\section{BIBLIOGRAFÍA}

AA.W. (1987): Prensa obrera en Madrid, 1855-1936, Madrid, Alfoz.

Álvarez, Jesús Timoteo (1981): Restauración y prensa de masas. Los engranajes de un sistema (1875-1883), Pamplona, EUNSA.

Álvarez, Jesús T. (ed.) (1989): Historia de los medios de comunicación en España. Periodismo, imagen y publicidad (1900-1990), Barcelona, Ariel.

Asenjo, Antonio (1933): La prensa madrileña a través de los siglos, Madrid, Artes gráficas municipales.

Cendán Pazos, Fernando (1974): Historia del derecho español de prensa e imprenta (1502-1966), Madrid, Editora Nacional.

Checa Godoy, Antonio (1989): Prensa y partidos políticos durante la II República, Salamanca, Universidad de Salamanca.

Desvois, Jean Michel (1977): La prensa en España (1900-1931), Madrid, Siglo XXI ed.

Espina, Antonio (1993): El cuarto poder. Cien años de periodismo español, Madrid, Ed. Libertarias-Prodhufi (1. ${ }^{\text {a ed., }}$ Madrid, Aguilar, 1960).

Recibido: 14 de mayo de 2010 Aceptado: 7 de junio de 2010
Gómez Aparicio, Pedro (1971): Historia del periodismo español, t. II;
De la revolución de septiembre al desastre colonial, Madrid, Editora Nacional.

Gómez Aparicio, Pedro (1974): Historia del periodismo español, t. III; De las guerras coloniales a la dictadura, Madrid, Editora Nacional.

Gómez Aparicio, Pedro (1981): Historia del periodismo español, t. IV; De la Dictadura a la Guerra Civil, Madrid, Editora Nacional.

López de Zuazo, A. (1981): Catálogo de periodistas españoles del siglo XX, Madrid.

Núñez Rey, Concepción (2005): Carmen de Burgos, Colombine, en la Edad de Plata de la cultura española, Sevilla, Fundación José Manuel Lara.

Ossorio y Bernard, M. (1903): Ensayo de un catálogo de Periodistas Españoles del siglo XIX, Madrid, Imprenta y litografía de J. Palacios.

Pizarroso Quintero, A. (1992): De la Gazeta Nueva a Canal Plus. Breve historia de los medios de comunicación en España, Madrid, Complutense.

Sánchez Aranda, J. J. y Barrera del Barrio, C. (1992): Historia del periodismo español. Desde sus orígenes hasta 1975 , Pamplona, EUNSA. 
Schulte, Henry F. (1968): The Spanish Press 1470-1966. Print, Power, and Politics, Urbana (III.), University of Illinois Press.

Seguin, Jean-Claude (1995): Historia del cine español, Madrid, Acento Editorial.

Seoane, M. ${ }^{a}$ Cruz (1983): Historia del periodismo en España, vol. 2. El siglo XIX Madrid, Alianza Ed.
Seoane, M. ${ }^{a}$ Cruz (1996): Historia del periodismo en España, vol. 3. El siglo XX, Madrid, Alianza Ed.

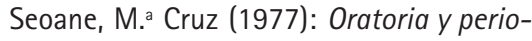
dismo en la España del S. XIX, Madrid, Ed. Castalia.

Tuñón de Lara, Manuel; Elorza, Antonio y Pérez Ledesma, M. (eds.) (1975): Prensa y sociedad en España (1820-
1936), Madrid, Ed. "Cuadernos para el Diálogo".

Valls, Josep-Francesc (1988): Prensa y burguesía en el XIX español, Barcelona, Anthropos.

Vigil y Vázquez, Manuel (1987): El periodismo enseñado. De la Escuela de "El Debate" a Ciencias de la Información, Barcelona, Mitre. 